\title{
ATIVISMO JUDICIAL E SUAS MÚLTIPLAS DEFINIÇÕES ${ }^{1}$
}

\section{JUDICIAL ACTIVISM AND ITS MULTIPLE DEFINITIONS}

Marco Félix Jobim

Mestre, Doutor, com estágio de Pós-doutor em Direito na Universidade Federal do Paraná (2015-2017). Professor Adjunto da Escola de Direito da PUC-RS na graduação, especialização, mestrado e doutorado. Coordenador da Especialização em Processo Civil e do Núcleo de Processo Civil da Escola de Direito da PUC-RS. Advogado. Secretário Adjunto do IBDP no Rio Grande do Sul. Porto Alegre/RS. Email:marco@jobimesalzano.com.br

\section{Zulmar Duarte de Oliveira Junior} Advogado. Consultor Jurídico. Especialista em Direito Civil e Direito Processual Civil. Professor da Unisul e de diversos Cursos de Pós-Graduação. Professor Convidado Permanente da Escola Superior da Advocacia - OAB/SC. Membro do IBDP (Instituto Brasileiro de Direito Processual), da ABDPro (Associação Brasileira de Direito Processual), do IAB (Instituto dos Advogados Brasileiros), do IASP (Instituto dos Advogados de São Paulo) e do CEAPRO (Centro de Estudos Avançados de Processo). Autor de diversos livros, artigos e pareceres com ênfase em Direito Processo Civil. Imbituba/SC.

RESUMO: O tema do ativismo judicial tem crescido cada dia mais no Brasil, não sendo poucos os trabalhos acadêmicos já existentes, mas também não tanto em volume. O estudo pretende demonstrar a existência do já iniciado debate em solo brasileiro, tendo como objeto a perquirição de qual o melhor conceito para saber da utilidade, ou não, da serventia da

\footnotetext{
${ }^{1}$ Artigo recebido em 16/06/2021 e aprovado em 20/07/2021.
} 
expressão. Não esquecem os autores da análise na literatura estrangeira, em especial a estadunidense, berço da criação da expressão judicial activism.

PAlAVRAS-CHAVE: Ativismo Judicial - Poder Judiciário - Criação do Direito Autocontenção Judicial.

ABSTRACT: The theme of judicial activism has grown more and more in Brazil, not existing only a few academic works, but also not so many in volume. The study intends to demonstrate the existence of the debate that has already started on Brazilian soil, with the object of investigating which is the best concept for knowing the usefulness, or not, of the functionality of the expression. Do not forgetting the authors of the analysis in foreign literature, especially the North American one, cradle of the creation of the expression judicial activism.

KEYWORDS: Judicial Activism - Judicial Power - Creation of Law - Judicial SelfContainment.

SUMÁRIO: Introdução. 1. Ativismo judicial. 1.1. A origem da expressão judicial activism. 1.2. O ativismo em outras tradições jurídicas. 1.3. Ativismo judicial e suas definições. 1.4. Ativismo judicial: uma primeira compreensão. Considerações finais. Referencial teórico.

Summary. Introduction. 1. Judicial activism. 1.1. The origin of the expression judicial activism. 1.2. Activism in other legal traditions. 1.3. Judicial activism and its definitions. 1.4. Judicial activism: a first comprehension. Final considerations. Theoretical references.

\section{INTRODUÇÃO.}

O presente texto não é uma tomada de posição a favor deste ou daquele ativismo (do bem ou do mal), menos ainda uma crítica às decisões ditas ativistas ou às decisões, no extremo oposto, predicadas como passivas - moderação ou discrição judicial (judicial selfrestraint). 
Em boa parte, a ideia do texto surgiu da constatação de que, por vezes, são taxadas negativamente como ativistas decisões que promovam direitos fundamentais a par da omissão dos demais poderes em realizá-los (Legislativo e Executivo). Porém, normalmente não se diz isso de decisões que, a despeito ou ao largo das regras processuais (com âmbito de proteção deficiente), verticalizem direitos processuais, potencializando o contraditório e a ampla defesa.

Ativistas seriam os juízes que implementam direitos fundamentais constitucionalmente estabelecidos, mas ainda não concretizados na prática constitucional? Ativistas seriam juízes que incrementem direitos processuais, amplificando o devido processo legal, estatuído como garantia constitucional, para além do regramento infraconstitucional? Correto seria o juiz que, diante de uma regra constitucional que estabeleça a proteção de um bem da vida, adote uma postura passiva mesmo quando presente omissão inconstitucional dos poderes constituídos em realizá-la?

Percebam que as cogitações são inúmeras e de difícil resposta. Não se pretende aqui apresentar soluções definitivas, pois apenas se compartilham as angústias e inquietações que levaram os autores a cogitar do tema.

De outra parte, não deixa de ser curioso, fora da ambiência jurídica a expressão ativismo é utilizada em uma perspectiva positiva, para qualificar como de vanguarda iniciativas ou pessoas que tenham capitaneado mudanças sociais significativas.

Betinho, Herbert José de Sousa, notabilizou-se como ativista dos direitos humanos, primeiro contra a ditadura, depois dedicando sua via ao projeto “Ação da Cidadania contra a Fome, a Miséria e pela Vida".

Quando o nome de Sean Penn foi anunciado na 81 ${ }^{\mathrm{a}}$ entrega do Oscar em 2009 com o prêmio de melhor ator pela sua atuação no filme Milk: a voz da liberdade, poucos sabiam que sua interpretação era baseada na vida do americano Harvey Milk $^{2}$, um defensor dos

\footnotetext{
${ }^{2}$ Um pouco da história de Harvey Milk pode ser conhecida na página da fundação Milk. Disponível em: https://milkfoundation.org/. Acesso 06 de maio de 2021. Sobre um pouco de sua história, está descrito na página da fundação: "Harvey Milk, was a visionary civil and human rights leader who became one of the first openly gay elected officials in the United States when he won a seat on the San Francisco Board of Supervisors in 1977. Milk's unprecedented loud and unapologetic proclamation of his authenticity as an openly gay candidate for public office, and his subsequent election gave never before experienced hope to Lesbian, Gay, Bisexual, and Transgendered (LGBT) people everywhere at a time when the community was encountering widespread hostility and discrimination. His remarkable career was tragically cut short when he was assassinated nearly a year after taking office".
} 
direitos humanos e dos direitos da comunidade "gay"3, eleito para o cargo público do conselho de supervisores, em 1977, tendo sido assassinado em novembro de 1978. Harvey Milk foi também um ativista!

Em 1964, um pastor negro chamado Martin Luther King, defensor da luta contra o racismo nos Estados Unidos da América, foi o grande agraciado com o Prêmio Nobel da Paz pelo seu trabalho em defesa da igualdade das raças. Uma de suas mais famosas frases, em discurso na histórica "Marcha de Washington", aos pés do memorial de Lincoln, que reuniu 250 mil pessoas, foi a de "Tenho um sonho de que meus quatro filhos viverão um dia em uma nação onde não serão julgados pela cor de sua pele, mas pelo teor de seu caráter”. Martin Luther King foi mais um ativista!

Em 1964, mesmo ano em que Martin Luther King ganhava o Nobel da Paz, Nelson Mandela estava sendo condenado à prisão perpétua, da qual foi libertado em 1990, ano em que, também, recebeu o prêmio Nobel. Mandela foi líder do movimento contra o regime do Apartheid (modelo de segregação racial existente na África do Sul) e, após ser solto, Presidente da nação africana. Nelson Mandela foi um outro ativista!

Em 1910 nascia Agnes Gonxha Bojaxhiu, em ÜsKüp, hoje Skopje, atual capital da Macedônia. Mais tarde, seu nome de nascimento foi esquecido, dando lado a um mais conhecido: Madre Teresa de Calcutá. A freira, defensora árdua da paz, realizou ações de caridade em prol dos mais pobres que lhe rendeu, em 1979, o Prêmio Nobel da Paz. Madre Teresa de Calcutá foi uma ativista.

A lista de personalidades nacionais e internacionais consideradas ativistas não pararia por aí e qualquer tentativa de esgotamento seria impossível de ser realizada, pois não se trata de lista estática, mas dinâmica. Mas nomes como Edward Burghardt Du Bois, Chico Mendes, Helen Keller, Antonio Gramsci, Rosa Parks, Malcolm X, Maria da Penha, Pierre Bourdieu, Malala Yousafzai e Mahatma Gandhi estão nessa lista. Vale lembrar, dentre as tantas bandeiras levantadas por Gandhi, duas se destacam: a primeira quando desobedeceu a comando de um juiz para retirada de seu turbante e a segunda quando voltou seus olhos para o enfrentamento do racismo ${ }^{4}$.

\footnotetext{
${ }^{3}$ Para fins de manutenção da historicidade, utiliza-se a palavra mais utilizada à época - gay - e não LGBTQIA+. ${ }^{4}$ PALMER, Joy A. 50 grandes educadores: de Confúcio a Dewey. Tradução de Mirna Pinsky. São Paulo: Contexto, 2008. p. 266. Escreve: "Mohandas Karamchand Gandhi, o arquiteto da liberdade da Índia pela luta sem violência, nasceu em 1869 em Porbander, um principado em Kathiawar, hoje Gujrat. Seu pai e avô foram ministros em Kathiawar. Depois de terminada a educação escolar, viajou para Londres a fim de estudar Direito.
} 
Revista Eletrônica de Direito Processual - REDP.

Rio de Janeiro. Ano 15. Volume 22. Número 3. Setembro a Dezembro de 2021

Periódico Quadrimestral da Pós-Graduação Stricto Sensu em Direito Processual da UERJ

Patrono: José Carlos Barbosa Moreira (in mem.). ISSN 1982-7636. pp. 710-731

www.redp.uerj.br

Hoje até mesmo organizações nacionais e internacionais estão na lista de serem consideradas ativistas, pelo modo como direcionam suas atividades, como o Greenpeace, o Conectas, Médicos sem Fronteiras, Cruz vermelha, dentre outras que são admiradas pelos seus trabalhos humanitários em todas as partes do globo.

Retoma-se o paralelo do início do texto: embora exista um consenso considerável, e mesmo admiração, ao trabalho realizado por esses atores sociais ativistas, tal não ocorre no Direito quando em pauta decisões que objetivam promover causas sociais ou direitos fundamentais constitucionalmente estabelecidos, porém de esquálida densidade normativa. Longe de nós pretender comparar o sacrifício pessoal, os resultados e a importância dos referidos ativistas socais com uma decisão judicial em si, cujo prolator sequer pretende, e não deveria pretender, considerar-se em si um ativista social.

A questão é do porquê o viés de iniciativa de uns (ativistas sociais) ser bem-visto, enquanto o viés de outro é objeto de crítica (ativismo judicial). Existe um verdadeiro desconforto com posições ativistas, sendo alvo de duras críticas por um lado e de defesas relevantes ${ }^{5}$ de outro ${ }^{6}$, como lembra Roger Stiefelmann Leal ${ }^{7}$. Eduardo José da Fonseca

\footnotetext{
Ao voltar, trabalhou como advogado em Bombai e Rajkot, sem sucesso. Um convite inesperado levou-o à África do Sul, onde duas experiências transformaram sua vida. A primeira ocorreu quando num tribunal de Durban o juiz lhe pediu que tirasse o turbante, o que feriu seu orgulho patriótico. A segunda realmente abriulhe os olhos para o racismo".

${ }^{5}$ Como o faz: TAVARES, André Ramos. Paradigmas de judicialismo constitucional. São Paulo: Saraiva, 2012. p. 63. Escreve: "É certo, ademais, que o termo 'ativismo', atrelado à ideia de um Estado Judicial, ao contrário do que ocorre em outros segmentos, assumiu uma conotação negativa. Neste estudo, contudo, seu uso é reputado como institucionalmente relevante e adequado, uma questão conceitual, como se pretende demonstrar".

${ }^{6}$ Keenan D. Kmiec. The Origin and Current Meanings of "Judicial Activism". California Law Review. Vol. 92. p. 1441. Escreve: "Speaking at a recent symposium, Judge Frank Easterbrook opened with an ostensibly safe sentence: "Everyone scorns judicial activism, that notoriously slippery term."' Yet even this observation cannot go unqualified. Most would agree that judicial activism is indeed slippery. But some scholars, 2 including at least one sitting Supreme Court Justice, 3 have suggested that in some contexts, it is not always a bad thing. This is the problem: one can scarcely make an observation about judicial activism today without appending definitions, provisos, and qualifications".

${ }^{7}$ GROSTEIN, Julio. Ativismo judicial: análise comparativa do direito constitucional brasileiro e norteamericano. São Paulo: Almedina, 2019. P. 11. Roger Stiefelmann Leal, ao apresentar a obra, escreve: "Mais recentemente, a mesma expressão - ativismo judicial - ganhou espaço em face da apreciação crítica constante de manifestação doutrinária sobre a atuação do judiciário brasileiro e, em particular, do Supremo Tribunal Federal. De um lado, a expressão tem sido adotada como evidente viés crítico, contemplando juízo de severa reprovação a determinados julgados e pronunciamentos em virtude de incorrerem em exercício indevido ou arbitrário da função jurisdicional. Ativismo judicial também tem servido, de outra parte, para descrever posicionamento heroico de juízes e tribunais, que, como último recurso, atendem relevantes anseios da sociedade em virtude de suposta resposta insatisfatória dos demais poderes políticos. Ou seja, seria a forma de fazer justiça, impondo parâmetros materiais de cunho ideológico, sobre os princípios da separação dos poderes e da democracia".
} 
$\operatorname{Costa}^{8}$ chega a denominar o que hoje ocorre no Brasil como um ativismo judicial tresloucado. Claro, como esclarece Marcelo Gleiser ${ }^{9}$, a percepção de mundo pode ser vista por ângulos diferentes, sem retirar de quem pensa diferente de outro a razão. É o ponto de vista ou a vista que parte de um ponto. O problema se agrava consideravelmente nas margens que o Poder Legislativo concede ao Judiciário, especificamente quando utiliza de conceitos jurídicos indeterminados ou tipos em disposições normativas que exigem a intervenção do último na densificação e concretização daqueles.

Parece cediço que a criação jurisprudencial necessita de diretrizes na ordem jurídicoconstitucional de um país, sob pena de usurpação de poder como refere Alexandre Sturion de Paula ${ }^{10}$. Ainda, não se pode tangenciar, algumas questões foram cristalizadas pelo legislador constituinte de antemão evitando interdições políticas ao seu debate por uma maioria ocasional ${ }^{11}$.

Em razão disso, o presente texto tem um propósito não ousado, mas absolutamente necessário, com o devido e merecido respeito. Caracterizar o que seria, na perspectiva dos autores, o ativismo judicial, tentando limpar o terreno para uma futura construção de um conceito de ativismo que permita servir como paradigma a crítica de excessos decisórios cometidos pelo Poder Judiciário ${ }^{12}$.

${ }^{8}$ COSTA, Eduardo José da Fonseca. A garantia dos processos jurisdional, administrativo e legislativo. Disponível em: https://emporiododireito.com.br/leitura/103-a-garanticidade-dos-processos-jurisdicionaladministrativo-e-legislativo. Acesso 16 de junho de 2021.

${ }^{9}$ GLEISER, Marcelo. A ilha do conhecimento: os limites da ciência e a busca por sentido. Rio de Janeiro: Record, 2014. p. 21. Aponta: "Eis outro modo de refletir sobre isso: se alguém percebe o mundo apenas através de seus sentidos (como a maioria das pessoas), enquanto outra pessoa amplia sua percepção através do uso de instrumentos diversos, quem tem um senso mais verdadeiro da realidade? Enquanto um 'vê' bactérias microscópicas, galáxias distantes e partículas subatômicas, para outro estas entidades não existem. Obviamente, se ambos baseiam seu conceito de realidade no que percebem, concluirão que suas visões de mundo são profundamente diferentes".

${ }^{10}$ PAULA, Alexandre Sturion de. Ativismo judicial no processo civil: limites e possibilidades constitucionais. Campinas, SP: Servanda, 2012. págs. 148-149. Escreve: "Neste escólio, Ativismo Judicial não deve erroneamente ser concebido como criação desenfreada do direito pelos juízes. O juiz não cria o direito do nada e se assim agisse estaríamos diante de um usurpador autoritário do poder. Porém, o direito não se resume ao positivado no ordenamento jurídico, de sorte que as decisões 'contra-legen' devem ser analisadas pela existência de lastro no sistema jurídico, mais amplo que o costumeiro e restrito legalismo saboreado incansavelmente por formalismos forenses".

${ }^{11}$ ELY, John Hart. Democracia e desconfiança: uma teoria do controle judicial de constitucionalidade. São Paulo: Martins Fontes, 2016. p. 13: "Naturalmente, é necessário estabelecer limitações colaterais ao governo da maioria, mas, como decidiram sabiamente os constituintes, é mais sábio e mais seguro estabelecê-las de antemão, antes de surgirem controvérsias específicas, do que desenvolvê-las no contexto de um problema político particular e das paranoias e paixões que o acompanham".

${ }^{12}$ LAURENTIS, Lucas Catib de. A proporcionalidade no direito constitucional: origem, modelos e reconstrução dogmática. São Paulo: Malheiros, 2017. p. 23. Escreve: "Há diferentes formas de se abordar um conceito. Descrever suas características e contornos, apresentar seus pressupostos, analisar seu funcionamento 


\section{Ativismo judicial.}

Para bem ou para o mal, o brasileiro tem tomado a dianteira em assuntos polêmicos, estando em plena produção nos mais variados temas no Direito que, até pouco tempo atrás, eram circunscritos a determinados países, como a própria questão dos precedentes que, somente após a virada do século XX para o XXI, iniciou a ter uma produção mais significativa em terrae brasilis com obras mais especializadas como a de Gustavo Santana Nogueira ${ }^{13}$ ou de Luiz Guilherme Marinoni ${ }^{14}$. Outra matéria que na virada do milênio iniciou a ser mais bem debatida no Brasil é a do presente estudo: o ativismo judicial, até em razão de existirem vozes ${ }^{15}$ que afirmam estar o fenômeno relacionado com a redemocratização que culminou com a promulgação da Constituição Federal de 1988.

Já existe significativa produção bibliográfica sobre ativismo judicial no Brasil, embora o tema esteja em plena efervescência, como aponta Carlos Alexandre de Azevedo Campos $^{16}$, mas nenhuma, até onde se conhece, atravessou o assunto do ativista ser, em outras áreas, um exemplo a ser seguido, admirado e estimulado, e no Direito uma feição autoritária a ser combatida - logo, nada admirável - no pensamento de muitos que escrevem e palestram sobre ele. Apenas a título ilustrativo inicial, obras como Ativismo judicial: análise

\footnotetext{
e lógica internos, são todas operações teóricas destinadas ao mesmo fim: expor, com clareza e detalhamento, um conceito ou noção. Os resultados que se espera alcançar com tal procedimento são a universalização de sua compreensão e a facilitação de sua aplicação".

${ }^{13}$ NOGUEIRA, Gustavo Santana. Stare decisis et non quieta movere: a vinculação aos precedentes no direito comparado e brasileiro. Rio de Janeiro: Lumen Juris, 2011.

${ }^{14}$ MARINONI, Luiz Guilherme. Precedentes obrigatórios. 6. ed. São Paulo: Revista dos Tribunais, 2019. A primeira edição data do ano de 2010.

${ }^{15}$ GARAU, Marilha Gabriela Reverendo; MULATINHO, Juliana Pessoa; REIS, Ana Beatriz Oliveira. Ativismo judicial e democracia: a atuação do STF e o exercício da cidadania no Brasil. In Revista Brasileira de Políticas Públicas. ISSN: 2236-1677. Volume 5, 2015. Disponível em: file:///C:/Users/MARCO/Downloads/3108-15489-1-PB.pdf. Acesso 16 de maio de 2021. p. 204. Escrevem: "A origem do ativismo judicial brasileiro encontra bases profundas na democracia oriunda, por sua vez, do processo de redemocratização que culminou na Constituição Federal de 1988. Essa constituição estabelece regime democrático centrado na representação, com poucas oportunidades de participação direta do cidadão no agir estatal, ainda que seja possível interpretar, a partir da leitura do seu artigo primeiro que o sistema político brasileiro é misto, ou seja, também consagra a participação social. Dessa forma, constitui-se uma democracia de baixa intensidade, que estimula o afastamento do cidadão da vida política, centrando a cidadania nas possibilidades do mercado".

${ }^{16}$ CAMPOS, Carlos Alexandre de Azevedo. A evolução do ativismo judicial na Suprema Corte NorteAmericana (I). Ano 2 (2013), no 6, 4693-4741 / http://www.idb-fdul.com/ ISSN: 2182-7567. Escreve: "Com isso, o ativismo judicial passou a ocupar, inevitavelmente, um espaço enorme em nossos debates doutrinários. Pode-se dizer, sem receio, que é um tema da moda. Não obstante, é de se assumir que estamos apenas engatinhando na temática do ativismo judicial".
} 
comparativa do direito constitucional brasileiro e norte-americano, de Julio Grostein ${ }^{17}$; Ativismo Judicial: parâmetros dogmáticos, de Elival da Silva Ramos ${ }^{18}$; Dimensões do ativismo judicial no STF, de Carlos Alexandre de Azevedo Campos ${ }^{19}$; jurisdição e ativismo judicial: limites da atuação do Judiciário, de Clarissa Tassinari ${ }^{20}$ e; Jurisdição constitucional e política: ativismo e autocontenção no STF, de Flávia Santiago Lima ${ }^{21}$, são apenas algumas das obras monográficas, inicialmente relatadas para demonstrar a já iniciada produção bibliográfica existente.

Também é inegável que, ao lado do tema do judicial review, outro se faz também bastante presente, que é do self restraint, que, no presente estudo, restará de fora, tendo em vista os limites existentes para artigos científicos em termos de objeto de debate. Para que não fique apenas no ar a afirmação, adota-se, nesse momento, a ideia exposta por André Ramos Tavares $^{22}$ quando aborda o tema e questiona que adotada a teoria da autocontenção judicial haveria uma deslegitimação do Poder Judiciário para atuação em áreas sensíveis, ainda mais com um texto constitucional como o brasileiro que adota uma atuação mais substantiva do juiz constitucional.

\subsection{A origem da expressão judicial activism.}

Como anteposto, ativismo, por si só, é um signo linguístico que é utilizado nas mais diversas áreas do pensamento humano e consegue, pelos exemplos de personalidades ou organizações, ter uma conotação altamente positiva. Porém, esse sentido não é apropriado pela dimensão jurídica, pois, quando se junta a ela o adjetivo judicial, formando a expressão "Ativismo Judicial", as críticas se acumulam exponencialmente, inclusive para alcançar

\footnotetext{
${ }^{17}$ GROSTEIN, Julio. Ativismo judicial: análise comparativa do direito constitucional brasileiro e norteamericano. São Paulo: Almedina, 2019.

${ }^{18}$ RAMOS, Elival da Silva. Ativismo Judicial: parâmetros dogmáticos. 2. ed. São Paulo: Saraiva, 2017.

${ }^{19}$ CAMPOS, Carlos Alexandre de Azevedo. Dimensões do ativismo no STF. Rio de Janeiro: Forense, 2014.

${ }^{20}$ TASSINARI, Clarissa. Ativismo judicial: limites da atuação do Judiciário. Porto Alegre: Livraria do Advogado, 2012.

${ }^{21}$ LIMA, Flávia Santiago. Jurisdição constitucional e política: ativismo e autocontenção no STF. Curitiba: Juruá, 2014.

${ }^{22}$ TAVARES, André Ramos. Paradigmas do judicialismo constitucional. São Paulo: Saraiva, 2012. p. 68. Defende: "Adotada de maneira ampla, a self restraint desemboca na deslegitimação do juiz constitucional para extensas áreas nas quais sua atuação tem sido decisiva e legítima. E essa desqualificação não é uma mera opção teórica; em muitos ordenamentos, especialmente quando a Constituição, como a brasileira, oferece sinais de adoção (e exigência) de uma atuação substantiva (ativista, se quiser) do juiz constitucional, como implementador da Constituição, a referida exclusão é dogmaticamente inadmissível".
} 
Revista Eletrônica de Direito Processual - REDP.

Rio de Janeiro. Ano 15. Volume 22. Número 3. Setembro a Dezembro de 2021

Periódico Quadrimestral da Pós-Graduação Stricto Sensu em Direito Processual da UERJ

Patrono: José Carlos Barbosa Moreira (in mem.). ISSN 1982-7636. pp. 710-731

www.redp.uerj.br

derivativos dessa postura ativista predicada como autoritária: até mesmo já se fala no âmbito jurídico no papel ativista do Ministério Público ${ }^{23}$, saindo do âmbito jurisdicional somente.

Perceba-se, não se está a dizer que em boa parte essas críticas sejam infundadas. $\mathrm{O}$ que se pretende é demonstrar que sob a rubrica "ativismo judicial" se embutem críticas que não tem relação propriamente com o que se deveria ler sob o epiteto "ativismo judicial". Isso porque, a expressão ativismo judicial passou a carimbam posturas autoritárias e inconstitucionais, que sem dúvida representam usurpação de poder, incidindo em excesso. Porém, possível uma leitura da expressão ativismo judicial que lhe reconduza a posturas judiciais que deem concreção ao ordenamento jurídico, principalmente constitucional, emprestando-lhe eficácia quando esvaziado por posturas institucionais omissivas, e inconstitucionais.

Por isso, inicialmente, parece ser interessante a averiguação o surgimento da expressão ativismo judicial, a fim de caracterizar seu sentido ordinário e, a partir daí, permitir delimitar sua resistência semântica ${ }^{24}$.

Em 1947, para demonstrar a atuação da Suprema Corte dos Estados Unidos da América, o consagrado historiador democrata estadunidense Arthur Meier Schlesinger publicou na Fortune Magazine um artigo denominado de "The Supreme Court: 1947”, sendo que nele, pela primeira vez, se identificou a expressão judicial activism. No Brasil, Carlos

\footnotetext{
${ }^{23}$ SILVA, Jussara Maria Pordeus e. Ativismo judicial e o papel do Ministério Público brasileiro na efetivação das políticas públicas: o caso Amazonas. In Ativismo judicial. Umberto Machado de Oliveira; Leonardo Fernandes dos Anjos (coords.). Curitiba: Juruá, 2010. p. 257. Escreve: "Por fim, revelou o papel ativista que o Ministério Público brasileiro, em especial o do Amazonas, vem desenvolvendo a partir da Constituição Federal de 1988, quando passou a ter a incombência de guardião da Constituição e do regime democrático [...]".

${ }^{24} \mathrm{O}$ texto sempre nos diz algo, sempre limita o campo das possibilidades: "Pode significar muitas coisas, mas há sentidos que seria despropositado sugerir" (ECO, Umberto. Interpretação e superinterpretação. São Paulo: Martins Fontes, 2016, p. 50). Toda interpretação se funda no entender. O que é como tal articulado na interpretação, e o que de antemão é delineado como articulável no entender em geral, é o sentido. (HEIDEGGER, Martin. Ser e tempo. Edição em alemão e português. Tradução e organização, nota prévia, anexos e notas Fausto Castilho. Campinas: Editora da Unicamp; Petrópolis: Vozes, 2012, p. 435). "A interpretação de algo como algo funda-se essencialmente por ter-prévio, ver-prévio e conceito-prévio. A interpretação nunca é uma apreensão sem-pressupostos de algo previamente dado [eines Vorgegebenen, de um já-dado]. Quando a concretização particular da interpretação, no sentido da interpretação exata de texto, apela de bom grado para o que de imediato 'está-aí', o que está aí de imediato nada mais é do que a indiscutida, e que-se-entende-por-si-mesma, opinião-prévia do intérprete, que ocorre necessariamente em todo princípio de interpretação como aquilo que já é 'posto' com a interpretação em geral, isto é, já é previamente dado no terprévio, no ver-prévio e no conceito-prévio" (HEIDEGGER, Martin. Ser e tempo. Edição em alemão e português. Tradução e organização, nota prévia, anexos e notas Fausto Castilho. Campinas: Editora da Unicamp; Petrópolis: Vozes, 2012, p. 427)
} 
Revista Eletrônica de Direito Processual - REDP.

Rio de Janeiro. Ano 15. Volume 22. Número 3. Setembro a Dezembro de 2021

Periódico Quadrimestral da Pós-Graduação Stricto Sensu em Direito Processual da UERJ

Patrono: José Carlos Barbosa Moreira (in mem.). ISSN 1982-7636. pp. 710-731

www.redp.uerj.br

Alexandre de Azevedo Campos ${ }^{25}$ historia a origem da expressão ativismo judicial na linha apresentada, referindo que Schlesinger, em seu estudo, defende que quanto mais uma Corte se apresenta de vital importância para seu país, mais ela será cobrada pelas suas escolhas. $\mathrm{Na}$ mesma linha Julio Grostein ${ }^{26}$ refere a mesma origem da expressão pela letra de Schlesinger, assim como Flávia Santiago $\operatorname{Lima}^{27}$ que, em complemento, refere que o artigo sequer tinha pretensões acadêmicas, mas tão só desmistificar o tribunal e seus componentes.

Assim, no plano norte-americano, pode-se constatar que a origem da expressão reside no artigo de Schlesinger, o que pode ser comprovado com a leitura de textos como The Origin and Current Meanings of 'Judicial Activism', de Keenan D. Kmiec ${ }^{28}$, artigo no qual explora alguns tópicos do texto de Schlesinger, informando que o historiador traçou o perfil dos justices da U. S. Supreme Court, alocando Black, Douglas, Murphy e Rutleg como ativistas, Frankfurter, Jackson e Burton como restritivos e Reed e o próprio Chief Justice à época Vinson como intermediários entre as duas posições.

Como curiosamente observa Keenan ${ }^{29}$, muitos estudiosos esperam encontrar o

${ }^{25}$ CAMPOS, Carlos Alexandre de Azevedo. A evolução do ativismo judicial na Suprema Corte NorteAmericana (I). Ano 2 (2013), n 6, 4693-4741 / http://www.idb-fdul.com/ ISSN: 2182-7567. Escreve: "A doutrina norte-americana reconhece que o primeiro uso público do termo "ativismo judicial" coube ao historiador estadunidense Arthur Schlesinger Jr.13 em um artigo intitulado The Supreme Court: 1947, publicado na Revista Fortune, vol. XXXV, nº 1, no mês de Janeiro de 1947. Nesse artigo, além de apresentar o termo, Schlesinger entregou outra importante lição: quanto mais uma corte se apresenta como uma instituição vital ao seu país e à sua sociedade, mais ela e seus membros deverão sujeitar-se a um julgamento crítico sobre suas motivações, relações internas e externas, enfim, tudo o que possa ser fator de suas decisões".

${ }^{26}$ GROSTEIN, Julio. Ativismo judicial: análise comparativa do direito constitucional brasileiro e norteamericano. São Paulo: Almedina, 2019. p. 77. Escreve: "Em janeiro de 1947, Arthur Schlesinger Jr., um historiador americano, publicou um artigo na Revista Fortune, intitulado The Supreme Court: 1947, no qual cunhou a expressão judicial activism".

${ }^{27}$ LIMA, Flávia Santiago. Jurisdição constitucional e política: ativismo e autocontenção no STF. Curitiba: Juruá, 2014. p. 164. Escreve: "O primeiro registro do termo ativismo judicial é creditado a uma reportage de 1947, da revista Fortune Magazine, denominado 'The Supreme Court'. No texto, o historiador democrata Arthur Schlesinger Jr., após descrever as relações pessoais, simpatias e inimizades entre os membros da corte, traça uma distinção entre os juízes 'ativistas' e os campeões da 'autorrestrição'. Por se tratar de um ensaio jornalístico, sem pretensões aced emicas, o objetivo do autor parecia ser a desmistificação do tribunal, e não propriamente uma avaliação do papal institucional da Suprema Corte daquele país".

${ }^{28}$ KMIEC, Keenan D. The Origin and Current Meanings of 'Judicial Activism'. California Law Review. Vol. 92, No. 5 (Oct., 2004). p. 1446. (pp. 1441-1477). Escreveu: “Arthur Schlesinger Jr. introduced the term "judicial activism" to the public in a Fortune magazine article in January 1947. Schlesinger's article profiled all nine Supreme Court justices on the Court at that time and explained the alliances and divisions among them. The article characterized Justices Black, Douglas, Murphy, and Rutlege as the "Judicial Activists" and Justices Frankfurter, Jackson, and Burton as the "Champions of Self Restraint. Justice Reed and Chief Justice Vinson comprised a middle group".

${ }^{29}$ KMIEC, Keenan D. The Origin and Current Meanings of 'Judicial Activism'. California Law Review. Vol. 92, No. 5 (Oct., 2004). pp. 1445/1446. (pp. 1441-1477). One might expect that the term "judicial activism" first appeared in a respected judge's dissent, or in a seminal law review article. This does not appear to be the case. 
Revista Eletrônica de Direito Processual - REDP.

Rio de Janeiro. Ano 15. Volume 22. Número 3. Setembro a Dezembro de 2021

Periódico Quadrimestral da Pós-Graduação Stricto Sensu em Direito Processual da UERJ

Patrono: José Carlos Barbosa Moreira (in mem.). ISSN 1982-7636. pp. 710-731

www.redp.uerj.br

judicial activism numa opinion dissidente de um Justice, mas foi num artigo em uma revista popular que foi ela utilizada pela primeira vez, somente sendo invocada pelo Poder Judiciário em 1967 pelo justice Joseph C. Hutcheson $\mathrm{Jr}^{30}$.

É praticamente uníssona a voz que considera o artigo na revista Fortune, de Schlesinger como o nascedouro da expressão judicial activism, sendo que, após tal fato, como escreve Thijmen Koopmans ${ }^{31}$, ela cruzou o Atlântico de se tornou tão corrente em outros locais como se usar calça jeans ou andar de automóveis da Ford.

\subsection{O ativismo em outras tradições jurídicas.}

O enfoque nesse momento não é o saber sobre o ativismo judicial no Brasil e nos Estados Unidos ${ }^{32}$, mas sim se outros países, de igual sorte, está se versando sobre o tema, problematizando-o, ainda que a título exemplificativo, como já radiografado pelo laboratório de análise jurisprudencial do Supremo Tribunal Federal ao anunciar o fenômeno existente também na Alemanha, Itália e Espanha ${ }^{33}$.

Em estudo sobre a Corte Colombiana, Rodrigo Nunes ${ }^{34}$ em artigo intitulado

Rather, somewhat fittingly, the first use of the term to attract substantial attention from the public occurred in a popular magazine, in an article meant for a general audience written by a non-lawyer.

30 OLIVEIRA, Umberto Machado de. Caso da limitação do uso de algemas: como delimitar o ativismo do Supremo Tribunal Federal? In Ativismo judicial. Umberto Machado de Oliveira; Leonardo Fernandes dos Anjos (coords.). Curitiba: Juruá, 2010. p. 196. Aduz: "O primeiro juiz a fazer referência a ativismo judicial foi Joseph C. Hutcheson Jr., em um voto que ignorou o julgamento proferido pelo então juiz distrital Skelly Wright, no caso Theriot v. Mercer [...]".

31 KOOPMANS, Thijmen. The roots of judicial activism. Disponível em: https://scholarlypublications.universiteitleiden.nl/handle/1887/22743. Acesso 8 maio de 2021. Escreve: "The expression. 'Judicial activism was coined in the United States, but it crossed the Atlantic and became as much part of our day-to-day experience as blue or Ford motor cars"

${ }^{32}$ Ficando em ambas as tradições, não se pode deixar de recomendar a leitura, na íntegra, de: GROSTEIN, Julio. Ativismo judicial: análise comparativa do direito constitucional brasileiro e norte-americano. São Paulo: Almedina, 2019.

${ }^{33}$ VALLE, Vanice Regina Lírio (org.). Ativismo jurisdicional e o Supremo Tribunal Federal: laboratório de análise jurisprudencial do STF. Curitiba: Juruá, 2009.

${ }^{34}$ Nunes, R. (2010). Ideational Origins of progressive Judicial Activism: The Colombian Constitutional Court and the Right to Health. Latin American Politics and Society, 52(3), 67-97. Doi: 10.1111/j.15482456.2010.00090.x.Nunes, R. (2010). Escreve: "Why are some newly empowered courts more likely than others to engage in progressive judicial activism? This paper addresses this question through an analysis of the origins and subsequent activism of the Colombian Constitutional Court towards rights in general, and the right to health in particular. My research suggests that ideational variables are the most effective in explaining this outcome. On the one hand, I argue that the Constitutional Court's behavior reflects the dominance within it of a particular set of ideas about the judicial role. On the other, I provide evidence that programmatic beliefs about the relationship between rule of law and market-driven economic growth led power holders to create the Court and to appoint judges of this orientation. The emergence of progressive judicial activism in 
Revista Eletrônica de Direito Processual - REDP.

Rio de Janeiro. Ano 15. Volume 22. Número 3. Setembro a Dezembro de 2021

Periódico Quadrimestral da Pós-Graduação Stricto Sensu em Direito Processual da UERJ

Patrono: José Carlos Barbosa Moreira (in mem.). ISSN 1982-7636. pp. 710-731

www.redp.uerj.br

\section{Ideational Origins of Progressive Judicial Activism: The Colombian Constitutional Court}

and the Right to Health, demonstra o franco crescimento do debate, em especial se intensificando depois dos anos 90 do século passado, e tendo a tema da saúde como um dos mais significativos envolvendo o ativismo judicial.

Já algum tempo se tem mencionado o ativismo judicial na Corte indiana, e R. Shunmugasundaram ${ }^{35}$, escrevendo sobre o tema no artigo Judicial activism and overreach in India, relata que as cortes não estão mais se mantendo passivas diante de situações de meramente retirar a lei da ordem jurídica ou prevenir que algo seja feito, sendo que nova atitudes em ações afirmativas tem sido a pauta, corrigindo o sistema com ordens e remédios processuais.

A Índia também anuncia por meio da doutrina discussões sobre a legitimidade do fenômeno, como escreve Arpita Saha, da National Law University, em Jodhpur, em artigo intitulado Judicial Activism in Indica: a necessary evil, título do qual já se traduz a preocupação com questões ligadas ao alcance do ativismo. Relata ele que nos últimos tempos os juízes da Suprema Corte têm atuado mais intensamente em $\operatorname{casos}^{36}$ que podem ser considerados ativistas, conquanto se saiba que as variadas conceituações existentes sobre o termo ${ }^{37}$ podem prejudicar o entendimento da matéria.

Colombia, my analysis suggests, was the unexpected outcome of purposeful political choices made by proponents of neoliberal economics".

${ }^{35}$ R. Shunmugasundaram. Judicial activism and overreach in India. Amicus Curiae Issue 72 Winter 2007. p. 23. Escreve: "Courts of today are not remaining passive, with the negative attitude of merely striking down a law or preventing something being done. The new attitude is towards positive affirmative actions, and issuing orders and decrees directing remedial actions".

${ }^{36}$ SAHA, Arpita, Judicial Activism in India: A Necessary Evil (July 8, 2008). Available at SSRN: https://ssrn.com/abstract=1156979 or http://dx.doi.org/10.2139/ssrn.1156979. Escreve: "Recently the country has seen instances of beneficial judicial activism to a great extent. High profile politician Shibu Soren has been convicted for a murder committed in 1994. Tinsel world celebrity Sanjay Dutt of Gandhigiri fame has been convicted of offences under the Arms Act committed in 1993. Navjyot Sidhu, an ex-cricketer with a gift of the gab has been convicted for aroad rage killing committed 18 years ago. Finally and most reassuringly for the public, the Delhi High Court has reversed a perverse decision of a lower court in the notorious case of murder of Jessica Lall some seven years ago. Manu Sharma's acquittal was a patent miscarriage of justice and there was a shrill public outcry. On appeal. The High Court has convicted Sharma, despite Ram Jethmalani's last minute pyrotechniques on behalf of Sharma. No doubt the mills of God (or justice) grind slowly "but they do so exceedingly small"'”.

${ }^{37}$ SAHA, Arpita, Judicial Activism in India: A Necessary Evil (July 8, 2008). Available at SSRN: https://ssrn.com/abstract=1156979 or http://dx.doi.org/10.2139/ssrn.1156979. Escreve: "Judicial activism has always been a source of heated debate, especially in the light of recent developments in this regard. Over the last few years with various controversial decisions, judges of the Supreme Court as well as various High Courts have once again triggered off the debate that has always generated a lot of heat. But still, what the term "judicial activism" actually connotes is still a mystery. From the inception of legal history till date, various critics have given various definitions of judicial activism, which are not only different but also contradictory. This is an 
Também o tema é discutido na Inglaterra, tradição na qual, como aponta Jerold L. Waltman $^{38}$, desde 1950, o debate se tornou mais frequente, com uma série de decisões que mudaram radicalmente o rumo das disputas acerca do judicial activism. O próprio desenvolvimento do direito inglês a partir do processo acentua tal característica: remedies procede rights ${ }^{39}$.

\subsection{Ativismo judicial e suas definições.}

É tarefa ingrata, e sem termo, a tentativa de delimitação da expressão "ativismo judicial”, ou até mesmo propugnar um mero acordo semântico ${ }^{40}$. Perceba-se, ademais, que utilizar seus antônimos, como paradigmas de definição por exclusão, não alcança resultados satisfatórios. Certamente, não seria adequado designar como comodistas ou passivos quem criticam tal postura de atuação. Ao que parece, a grande maioria dos críticos ao "ativismo judicial" estaria no meio do caminho, adotando a máxima da sensatez cartesiana — o meio do caminho é melhor do que seus extremos ${ }^{41}$.

André Luiz Fernandes Fellet ${ }^{42}$, em apresentação à obra específica sobre o tema, refere que se trata de uma verdadeira jornada a tentativa de desvelamento do conceito de

attempt to bring out the exact connotation of "judicial activism" and to find out its effects on today's changing Society".

${ }^{38}$ WALTMAN, Jerold L. Judicial Activism in England. In Judicial Activism in Comparative Perspective. pp 33-52. Aduz: "'Judicial activism' is a term that sits uncomfortably with English constitutional theory, political culture, and with the judges themselves. Yet, it is now applied regularly to the behavior of English judges. John Griffith refers to 'a period of judicial activism or intervention which began in the early 1960s and has been growing in strength ever since. While discussing the evolving law of public duties A. J. Harding stressed the importance of 'the winds of the new judicial activism. Even a senior British judge offered the following assessment in 1985: 'Today it is perhaps commonplace to observe that as a result of a series of judicial decisions since about 1950 ... there has been a dramatic and indeed a radical change. That change has been described- by no means critically- as an upsurge of judicial activism."'

${ }^{39}$ DAVID, René. Os grandes sistemas do direito contemporâneo. 4. ed. Tradução de Hermínio A. Carvalho. São Paulo: Martins Fontes, 2002, p. 363e 368.

${ }^{40}$ TASSINARI, Clarissa. Jurisdição e ativismo judicial: limites da atuação do Poder Judiciário. Porto Alegre: Livraria do Advogado, 2013. p. 147. Escreve: "No âmbito da doutrina brasileira, há certa dificuldade de, ao menos, fixar-se um acordo semântico do que seja o ativismo judicial, de modo que tal postura acaba revelandose basicamente como uma exagerada interferência do Judiciário na sociedade (protagonismo judicial), ou, então, termina sendo aleatoriamente invocado na tomada de decisões através de critérios de conveniência".

${ }^{41}$ DESCARTES, René. Discurso del método; meditaciones metafísicas. Madrid: LIBSA, 2001.

${ }^{42}$ FELLET, André Luiz Fernandes. As novas faces do ativismo judicial. André Luiz Fernandes Fellet; Daniel Giotti de Paula; Marcelo Novelino (orgs.). Salvador: JusPodivm, 2011. p. 13. Escreve "É com essa observação que se propõe iniciar a jornada a ser empreendida nas páginas que se seguem, com o fito específico de desvelarse o conceito de 'ativismo judicial', de forma que, através de uma fixação mais precisa e clara de seus contornos, se possa analisar criticamente as atuações de membros do Poder Judiciário, apartando-se as práticas ultra vires e à ideias de justiça intersubjetivamente compartilhados, efetivando a Constituição e as leis”. 
Revista Eletrônica de Direito Processual - REDP.

Rio de Janeiro. Ano 15. Volume 22. Número 3. Setembro a Dezembro de 2021

Periódico Quadrimestral da Pós-Graduação Stricto Sensu em Direito Processual da UERJ

Patrono: José Carlos Barbosa Moreira (in mem.). ISSN 1982-7636. pp. 710-731

www.redp.uerj.br

ativismo judicial. Por isso, não se pode confiar em conceituação de dicionários jurídicos ${ }^{43}$ que, muitas vezes, apenas orientam para uma das faces somente do ativismo judicial.

Cogite-se, como se adjetivar uma prática como ativista, sem antes determinar sua definição, positiva ou negativa, como lembra Gustavo Just ${ }^{44}$. Joana de Souza Machado ${ }^{45}$ lembra que é tão fluída a conceituação do termo que liberais a utilizaram ao longo da história para criticar decisões conservadoras, e conservadores, de igual forma, a criticaram em decisões ditas mais liberais.

Pois bem, um dos primeiros a parte a se realizar no contexto do conceito de ativismo judicial é levantado por Elival da Silva Ramos ${ }^{46}$ em sua tese de titularidade para Professor de Direito Constitucional da Faculdade de Direito de São Paulo, quando expõe que para estudar ativismo é necessário o olhar ao direito comparado, pois se trata de fenômeno que pode ser recepcionado diferentemente em cada contexto interno do país a ser estudado. Nas palavras de J. J. Gomes Canotilho ${ }^{47}$, a questão do ativismo judicial é uma floresta problemática, enredada em ambiente jurídico-político-constitucional e que nunca,

43 Como é o caso de: MELLO, Maria Chaves de. Dicionário jurídico português-inglês - inglêsportuguês/Portuguese-English-English-Portuguese. 9a . ed. Rio de Janeiro: Forense; São Paulo: MÉTODO, 2009. p. 811. Escreve assim no verbete Judicial Activism: "Ativismo judiciário (ocorre quando o juiz utiliza a função como meio de alcançar objetivos políticos e sociais, invadindo o campo de atribuições do Legislativo e do Executivo".

${ }^{44}$ LIMA, Flávia Santiago. Jurisdição constitucional e política: ativismo e autocontenção no STF. Curitiba: Juruá, 2014. p. 12. Gustavo Just, ao escrever o prefácio da versão comercial da tese de doutorado da autora, expõe: "Concluir se o Supremo, ou qualquer Corte constitucional ou órgão judicial, é ou não ativista é algo que depende essencialmente de como se define 'ativismo judicial"'.

${ }^{45}$ MACHADO, Joana de Souza. Dissertação de mestrado. Ativismo judicial no Supremo Tribunal Federal. Programa de Pós-graduação em Teoria do Estado e Direito Constitucional da PUC-Rio. Disponível em: http://www.dominiopublico.gov.br/download/teste/arqs/cp077037.pdf. Acesso 15 de maio de 2021. p. 16. Escreve: "A expressão "ativismo judicial” já foi utilizada por conservadores como referência pejorativa a jurisdições de perfil liberal; não escapou, ainda, da apropriação dos liberais, que, por sua vez, usaram-na para fazer menção negativa a jurisdições de perfil conservador".

${ }^{46}$ RAMOS, Elival da Silva. Ativismo judicial: parâmetros dogmáticos. São Paulo: Saraiva, 2010. p. 104. Escreve: "Em um mundo integrado como aquele que vivemos é desnecessário insistir na importância do estudo do Direito Comparado, dadas as múltiplas influências entre os diversos sistema jurídicos. Na temática escolhida, entretanto, é fundamental a visão comparatística, porquanto se a caracterização do ativismo judicial importa na avaliação do modo de exercício da função jurisdicional, o fenômeno será percebido diferentemente de acordo com o papel institucional que se atribua em cada sistema ao Poder Judiciário".

${ }^{47}$ CANOTILHO, J. J. Gomes. Ativismo judicial. Umberto Machado de Oliveira; Leonardo Fernandes dos Anjos (coords.). Curitiba: Juruá, 2010. p. 9. Escreve no prefácio à obra: “Alguns parceiros de diálogo aceitaram o desafio e analisam a temática do ecological approuch judicial para aprofundarem algumas dimensões da 'floresta problemática' do ativismo. Todos sabemos que o ativismo judicial coloca problemas jurídico-políticoconstitucionais de separação e interdependência de poderes. Não é desconhecido por ninguém que são de inequívoca complexidade as incidências metódico-metodológicas das práticas judiciário-ativistas. Tão pouco se ignora a ambience político-social em que se desenvolvem alguns dos 'caso' conducentes a arestos judiciais inspirados pela ideia de conformação ativa das políticas públicas", e finaliza: "O assunto do ativismo nunca está esgotado". 
Revista Eletrônica de Direito Processual - REDP.

Rio de Janeiro. Ano 15. Volume 22. Número 3. Setembro a Dezembro de 2021

Periódico Quadrimestral da Pós-Graduação Stricto Sensu em Direito Processual da UERJ

Patrono: José Carlos Barbosa Moreira (in mem.). ISSN 1982-7636. pp. 710-731

www.redp.uerj.br

verdadeiramente, será esgotado.

Para se ter uma ideia da diversidade de visões, Vladimir Santos Vitovsky ${ }^{48}$, invocando a conhecida decisão do juiz Magnaud ${ }^{49}$, aposta no conceito de ativismo judicial para defini-lo como uma expansão do exercício da discricionariedade judicial, afastando a aplicação do direito legislador para poder promover judicial overreaching ou incentivar policy making, apostando que o ativismo nutre em seu objeto uma luta contra o positivismo, embora Luis Fernando Barzotto $^{50}$ defenda que tanto a matriz positivista como a

${ }^{48}$ VITOVSKY, Vladimir Santos. Activismo judicial: só pecados e virtudes? Contribuições para uma teoria sociojurídica. In Ativismo judicial. Umberto Machado de Oliveira; Leonardo Fernandes dos Anjos (coords.). Curitiba: Juruá, 2010. p. 91. Inicia escrevendo: “O juiz Magnaud torna-se célebre no meio judiciário pelos seus julgados, aplicando mais a equidade do que a letra fria da lei. Trata-se de um caso notório de ativismo judicial, de rejeição ao legalismo, e que nos auxilia a ilustrar um dos principais e mais conhecidos aspectos do ativismo judicial: a luta contra o positivismo, a não aplicação da lei em seu sentido estrito", e finaliza: "Em suas definições correntes, o ativismo judicial é uma expressão do exercício da discricionariedade judicial, no qual um juiz ou um Tribunal cria ou estende um direito, afasta a aplicação da lei, ou utiliza-se do poder judicial para promover mudanças sociais (judicial overreaching) e intervir ou efetivar políticas públicas (policy making)".

49 "Présidence de M. Magnaud Le Tribunal, Attendu que la fille Ménard, prévenue de vol, reconnaît avoir pris un pain dans la boutique du boulanger Pierre, qu'elle exprime sincèrement ses regrets de s'être laissé aller à commettre cet acte; Attendu que la prévenue a à sa charge un enfant de deux ans pour lequel personne ne lui vient en aide, et que, depuis un certain temps, elle est sans travail malgré ses recherches pour s'en procurer; qu'elle est bien notée dans la commune et passe pour laborieuse et bonne mère; qu'en ce moment, elle n'a pour toute ressource que le pain de deux kilos et les deux livres de viande que lui délivre chaque semaine le bureau de bienfaisance de Charly, pour elle, sa mère et son enfant; Attendu qu'au moment où la prévenue a pris un pain chez le boulanger Pierre, elle n'avait pas d'argent et que les denrées qu'elle avait reçues étaient épuisées depuis trente-six heures; que ni elle, ni sa mère n'avaient mangé pendant ce laps de temps, laissant pour l'enfant les quelques gouttes de lait qui étaient dans la maison; qu'il est regrettable que dans une société bien organisée, un des membres de cette "société", surtout une mère de famille, puisse manquer de pain autrement que par sa faute; que lorsqu'une pareille situation se présente et qu'elle est, comme pour Louise Ménard, très nettement établie, le juge peut, et doit, interpréter humainement les inflexibles prescriptions de la loi; Attendu que la faim est susceptible d'enlever à tout être humain une partie de son libre arbitre et d'amoindrir en lui, dans une grande mesure, la notion du bien et du mal; Qu'un acte ordinairement répréhensible perd beaucoup de son caractère frauduleux, lorsque celui qui le commet n'agit que poussé par l'impérieux besoin de se procurer un aliment de première nécessité, sans lequel la nature se refuse à mettre en oeuvre notre constitution physique; Que l'intention frauduleuse est encore bien plus atténuée lorsqu'aux tortures aiguës résultant d'une longue privation de nourriture, vient se joindre comme dans l'espèce, le désir si naturel chez une mère de les éviter au jeune enfant dont elle a la charge; Qu'il en résulte que tous les caractères de la préhension frauduleuse librement et volontairement perpétrée ne se retrouvent pas dans le fait accompli par Louise Ménard qui s'offre à désintéresser le boulanger Pierre sur le premier travail qu'elle pourra se procurer; Que si certains états pathologiques, notamment l'état de grossesse, ont souvent permis de relaxer comme irresponsables les auteurs de vols accomplis sans nécessité, cette irresponsabilité doit, à plus forte raison, être admise en faveur de ceux qui n'ont agi sous l'irrésistible impulsion de la faim; Qu'il y a lieu en conséquence, de renvoyer la prévenue des fins de poursuites, sans dépens et ce, par application de l'article 64 du Code Penal. Par ces motifs, le tribunal renvoie Louise Ménard des fins de poursuites, sans dépens. (original du jugement aux Archives de l'Aisne, fonds du Tribunal de première instance de Château-Thierry 25 U 61)". Disponível em: <http://www.lafontaine-ch-thierry.net/socmagn.htm>. Acesso em: 14 de maio de 2021.

${ }^{50}$ BARZOTTO, Luis Fernando. Teoria do direito. Porto Alegre: Livraria do Advogado, 2017. p. 11. Escreve: "A tese do presente texto é que dois dos paradigmas jurídicos mais difundidos na teoria jurídica contemporânea, o positivismo, na vertente kelseniana, e o neoconstitucionalismo, são concepções que favorecem o ativismo judicial ao desvincular o juiz do direito expresso na lei". 
neoconstitucionalista favoreçam o ativismo judicial.

\subsection{Ativismo judicial: uma primeira compreensão}

O juiz da autocontenção judicial terá algum dia em sua vida uma decisão ativista? O juiz ativista está proibido de tomar posturas de autocontenção? Thomas M. Keck ${ }^{51}$ coloca em pauta esse debate ao narrar a decisão da recontagem de votos na Florida no caso Bush v. Gore, quando os justices conservadores, críticos intensos do "governmente by judiciary", proibiram a continuidade da recontagem dos votos, confrontando expressamente a cláusula da décima quarta emenda à Constituição que garante a igualdade de proteção.

Como dito, a palavra ativismo encontra conotação positiva em diversas personalidades e organismos internacionais, mas quando a ela se junta o adjetivo judicial, formado a expressão ativismo judicial, os pensadores que se dedicam ao tema na área jurídica divergem em argumentos prós e contra, sob as mais diversas justificações. Não é possível que à luz de toda informação existente em pleno século XXI não possamos criar possibilidades mais democratizadas de atuação judicial, como, por exemplo, fizeram Flavia Danielle Santiago Lima e Eduarda Peixoto da Cunha França ${ }^{52}$ ao combaterem o ativismo antidialógico.

Em nossa perspectiva, frente à ambiguidade conotativa da expressão, possível a (re)construção de um conceito de ativismo judicial que não seja negativo, mas que possa expressar uma postura hermenêutica ativa no emprestar eficácia plena e integral ao direito positivo, mormente de matriz constitucional.

\footnotetext{
${ }^{51}$ KECK, Thomas M. The most activist Court in history: the Road to modern judicial conservatism. Chicago: The University of Chicago Press, 2004. p. 1. Escreve: "On December 12, 2000, the U. S. Supreme Court decided the outcome of the nation's presidential election by a single judicial vote. In Bush v. Gore, the Court's five most conservative justices halted the ongoing ballot recount in Florida - a recount that, so far as anyone knew at the time, might well have resulted in Democrat Al Gore's election. The conservative's justices called the contest to a close, ruling that the Equal Protection Clause of the Fourteenth Amendment prohibited the recount from continuing. This decision was surprising to many observers these same conservatives justices had long been known for their critique of 'government by judiciary', and because vote-continuing in a democratic election represents precisely the sort of 'political thicket' the conservatives had on urged courts to avoid".

${ }^{52}$ LIMA, Flavia Danielle Santiago; FRANÇA, Eduarda Peixoto da Cunha. Repensando o papel da jurisdição nos litígios estruturais de interesse público: do ativismo antidialógico à decisão compartilhada. In Revista Eletrônica de Direito Processual - REDP Rio de Janeiro. Ano 15. Volume 22. Número 1. Janeiro a Abril de 2021 Periódico Quadrimestral da Pós-Graduação Stricto Sensu em Direito Processual da UERJ Patrono: José Carlos Barbosa Moreira (in mem.). ISSN 1982-7636. pp. 350-378 www.redp.uerj.br. Acesso 16 de junho de 2021.
} 
Ativismo judicial, ativismo na dimensão judicial corretamente visualizado, é a postura judicial ativa no exercício da função jurisdicional. Isto é, a resolução dos conflitos a partir do direito positivo, em toda sua plenitude e eficácia, sem diminuir ou reduzir as possibilidades de desenvolvimento dos seus comandos no que atrelados a tal finalidade.

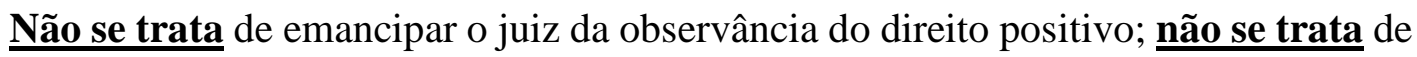
outorgar mandato para que o juiz construa disposições normativas a partir dos seus juízos de oportunidade e conveniência; não se trata de possibilitar ao juiz, com base em visões abstratas sobre conceitos jurídicos, a construção de textos normativos casuísticos.

Trata-se, porém, de evitar a perpetuação de omissões na aplicação do direito positivo, cujos núcleos deônticos sejam claros, sob o argumento da necessidade de atuação de outros poderes que inconstitucionalmente, ou ilegalmente, abstêm-se; trata-se de evitar que o monopólio da atividade jurisdicional seja esvaziado por posturas abstencionistas na resolução de conflitos que sejam submetidos ao Poder Judiciário; trata-se de permitir a aplicação do direito por parte do juiz quando chamado a desenvolvê-lo pelo Poder Legislativo, pela utilização de conceitos jurídicos determinados, conceitos ou tipos abertos.

Pensar o ativismo judicial a partir de tal perspectiva, descontaminando seu âmbito de sentido, desloca os problemas dos excessos cometidos pelo Poder Judiciário para os confins, para além da expressão. Da mesma forma, uma decisão passiva, comodista, que não empresa eficácia às regras de direito positivo do sistema, também pode ser considerada negativa, na dimensão do que "poderia expressar ou realizar".

Tanto desaplica o direito positivo aquele que ultrapassa seus limites, quanto aquele que não perfaz o seu raio de abrangência.

Logo, a expressão ativismo judicial, em tal compreensão, passa a ter uma conotação neutra (nem positiva, tampouco negativa), representando posturas judiciais ativas no desenvolvimento do direito, mas sem ultrapassar seus limites, respeitando a tradição. Decisões que usurpem espaços destinados à atuação dos demais poderes não são exemplos de "ativismo judicial", mas simplesmente arquétipos de "usurpação judicial". Porém, a outra face do fenômeno não merece ser prestigiada, tampouco louvada, decisões abstencionistas são igualmente deletérias e corroem a eficácia do direito positivo, não sendo modelos de sobriedade (ou discrição) judicial. 


\section{Considerações finais.}

Talvez se devam encontrar expressões que melhor traduzam, se é que no Brasil ativismo judicial ficará manchada apenas por suas conotações negativas, as diferenças existentes inseridas dentro das capacidades e competências que o Poder Judiciário exerce.

Ao lado do ativismo judicial, poder-se-ia alocar mais o adjetivo monológico para que as críticas sejam pertinentes nessa forma de atuação solitária exercida, ainda, por alguns juízes. Na outra extremidade, estaria a self-restraint, como forma de contraposição ao ativismo judicial monológico, mesmo que, como já referido, se tenha na autocontenção a possibilidade do exercício de ativismo.

Então, uma proposta interessante, é o que já vem ocorrendo como um meio termo entre o ativismo monológico e a autocontenção judicial, que seria o ativismo judicial dialógico, equilibrando a atividade jurisdicional a partir de um profícuo debate, ouvindo partes, interessados, demais poderes e sociedade civil em geral, por meio das técnicas já existentes e possíveis outras, o que responderia, em muito, críticas feitas a expressão em sua forma original.

\section{REFERÊNCIAS}

BARZOTTO, Luis Fernando. Teoria do direito. Porto Alegre: Livraria do Advogado, 2017. CAMPOS, Carlos Alexandre de Azevedo. A evolução do ativismo judicial na Suprema Corte Norte-Americana (I). Ano 2 (2013), n 6, 4693-4741 / http://www.idbfdul.com/ ISSN: 2182-7567.

CAMPOS, Carlos Alexandre de Azevedo. Dimensões do ativismo no STF. Rio de Janeiro: Forense, 2014.

CANOTILHO, J. J. Gomes. Ativismo judicial. Umberto Machado de Oliveira; Leonardo 
Fernandes dos Anjos (coords.). Curitiba: Juruá, 2010.

COSTA, Eduardo José da Fonseca. A garantia dos processos jurisdional, administrativo e legislativo. Disponível em: https://emporiododireito.com.br/leitura/103-agaranticidade-dos-processos-jurisdicional-administrativo-e-legislativo. Acesso 16 de junho de 2021.

DAVID, René. Os grandes sistemas do direito contemporâneo. 4. ed. Tradução de Hermínio A. Carvalho. São Paulo: Martins Fontes, 2002.

DESCARTES, René. Discurso del método; meditaciones metafísicas. Madrid: LIBSA, 2001 .

ECO, Umberto. Interpretação e superinterpretação. São Paulo: Martins Fontes, 2016.

ELY, John Hart. Democracia e desconfiança: uma teoria do controle judicial de constitucionalidade. São Paulo: Martins Fontes, 2016.

FELLET, André Luiz Fernandes. As novas faces do ativismo judicial. André Luiz Fernandes Fellet; Daniel Giotti de Paula; Marcelo Novelino (orgs.). Salvador: JusPodivm, 2011.

GARAU, Marilha Gabriela Reverendo; MULATINHO, Juliana Pessoa; REIS, Ana Beatriz Oliveira. Ativismo judicial e democracia: a atuação do STF e o exercício da cidadania no Brasil. In Revista Brasileira de Políticas Públicas. ISSN: 2236-1677. Volume 5, 2015. Disponível em: file:///C:/Users/MARCO/Downloads/3108-15489-1PB.pdf. Acesso 16 de maio de 2021. págs. 191-206.

GLEISER, Marcelo. A ilha do conhecimento: os limites da ciência e a busca por sentido. Rio de Janeiro: Record, 2014.

GROSTEIN, Julio. Ativismo judicial: análise comparativa do direito constitucional brasileiro e norte-americano. São Paulo: Almedina, 2019.

HARVEY MILK. https://milkfoundation.org/. Acesso 06 de maio de 2021.

HEIDEGGER, Martin. Ser e tempo. Edição em alemão e português. Tradução e organização, nota prévia, anexos e notas Fausto Castilho. Campinas: Editora da Unicamp; Petrópolis: Vozes, 2012.

KECK, Thomas M. The most activist Court in history: the Road to modern judicial conservatism. Chicago: The University of Chicago Press, 2004.

KMIEC, Keenan D. The Origin and Current Meanings of 'Judicial Activism'. California Law 
Review. Vol. 92, No. 5 (Oct., 2004). p. 1446. (pp. 1441-1477).

KOOPMANS, Thijmen. The roots of judicial activism. Disponível em: https://scholarlypublications.universiteitleiden.nl/handle/1887/22743. Acesso 8 maio de 2021.

LAURENTIS, Lucas Catib de. A proporcionalidade no direito constitucional: origem, modelos e reconstrução dogmática. São Paulo: Malheiros, 2017.

LE JUGE MAGNAUD. Disponível em: <http://www.la-fontaine-chthierry.net/socmagn.htm>. Acesso em: 14 de maio de 2021.

LIMA, Flávia Santiago. Jurisdição constitucional e política: ativismo e autocontenção no STF. Curitiba: Juruá, 2014.

LIMA, Flavia Danielle Santiago; FRANÇA, Eduarda Peixoto da Cunha. Repensando o papel da jurisdição nos litígios estruturais de interesse público: do ativismo antidialógico à decisão compartilhada. In Revista Eletrônica de Direito Processual - REDP Rio de Janeiro. Ano 15. Volume 22. Número 1. Janeiro a Abril de 2021 Periódico Quadrimestral da Pós-Graduação Stricto Sensu em Direito Processual da UERJ Patrono: José Carlos Barbosa Moreira (in mem.). ISSN 1982-7636. pp. 350-378 www.redp.uerj.br. Acesso 16 de junho de 2021.

MACHADO, Joana de Souza. Dissertação de mestrado. Ativismo judicial no Supremo Tribunal Federal. Programa de Pós-graduação em Teoria do Estado e Direito Constitucional da PUC-Rio. Disponível em: http://www.dominiopublico.gov.br/download/teste/arqs/cp077037.pdf. Acesso 15 de maio de 2021.

MARINONI, Luiz Guilherme. Precedentes obrigatórios. 6. ed. São Paulo: Revista dos Tribunais, 2019.

MELlO, Maria Chaves de. Dicionário jurídico português-inglês - inglêsportuguês/Portuguese-English-English-Portuguese. 9 9 $^{\mathrm{a}}$. ed. Rio de Janeiro: Forense; São Paulo: MÉTODO, 2009.

NOGUEIRA, Gustavo Santana. Stare decisis et non quieta movere: a vinculação aos precedentes no direito comparado e brasileiro. Rio de Janeiro: Lumen Juris, 2011.

NUNES, R. (2010). Ideational Origins of progressive Judicial Activism: The Colombian Constitutional Court and the Right to Health. Latin American Politics and Society, 
52(3), 67-97. Doi: 10.1111/j.1548-2456.2010.00090.x.Nunes, R. (2010).

PALMER, Joy A. 50 grandes educadores: de Confúcio a Dewey. Tradução de Mirna Pinsky. São Paulo: Contexto, 2008.

OLIVEIRA, Umberto Machado de. Caso da limitação do uso de algemas: como delimitar o ativismo do Supremo Tribunal Federal? In Ativismo judicial. Umberto Machado de Oliveira; Leonardo Fernandes dos Anjos (coords.). Curitiba: Juruá, 2010. Págs. 175253.

PAULA, Alexandre Sturion de. Ativismo judicial no processo civil: limites e possibilidades constitucionais. Campinas, SP: Servanda, 2012.

R. Shunmugasundaram. Judicial activism and overreach in India. Amicus Curiae Issue 72 Winter 2007.

RAMOS, Elival da Silva. Ativismo judicial: parâmetros dogmáticos. São Paulo: Saraiva, 2010.

RAMOS, Elival da Silva. Ativismo Judicial: parâmetros dogmáticos. 2. ed. São Paulo: Saraiva, 2017.

SAHA, Arpita, Judicial Activism in India: A Necessary Evil (July 8, 2008). Available at SSRN: https://ssrn.com/abstract=1156979 http://dx.doi.org/10.2139/ssrn.1156979.

SILVA, Jussara Maria Pordeus e. Ativismo judicial e o papel do Ministério Público brasileiro na efetivação das políticas públicas: o caso Amazonas. In Ativismo judicial. Umberto Machado de Oliveira; Leonardo Fernandes dos Anjos (coords.). Curitiba: Juruá, 2010. págs. 255-295.

TASSINARI, Clarissa. Ativismo judicial: limites da atuação do Judiciário. Porto Alegre: Livraria do Advogado, 2012.

TAVARES, André Ramos. Paradigmas de judicialismo constitucional. São Paulo: Saraiva, 2012.

VALLE, Vanice Regina Lírio (org.). Ativismo jurisdicional e o Supremo Tribunal Federal: laboratório de análise jurisprudencial do STF. Curitiba: Juruá, 2009.

VITOVSKY, Vladimir Santos. Activismo judicial: só pecados e virtudes? Contribuições para uma teoria sociojurídica. In Ativismo judicial. Umberto Machado de Oliveira; Leonardo Fernandes dos Anjos (coords.). Curitiba: Juruá, 2010. págs. 89-136. 
Revista Eletrônica de Direito Processual - REDP.

Rio de Janeiro. Ano 15. Volume 22. Número 3. Setembro a Dezembro de 2021

Periódico Quadrimestral da Pós-Graduação Stricto Sensu em Direito Processual da UERJ

Patrono: José Carlos Barbosa Moreira (in mem.). ISSN 1982-7636. pp. 710-731

www.redp.uerj.br

WALTMAN, Jerold L. Judicial Activism in England. In Judicial Activism in

Comparative Perspective. pp 33-52. 